\title{
Acid-Free Nitration of Benzene and Toluene in Zeolite NaZSM-5
}

\author{
Scott J. Kirkby \\ Department of Chemistry, East Tennessee State University, P.O. Box 70695, Johnson City, TN 37614, USA \\ Correspondence should be addressed to Scott J. Kirkby; kirkby@etsu.edu
}

Received 20 December 2012; Accepted 22 January 2013

Academic Editors: F. M. Cabrerizo, B.-T. Liu, X. Rozanska, and E. Yeow

Copyright (c) 2013 Scott J. Kirkby. This is an open access article distributed under the Creative Commons Attribution License, which permits unrestricted use, distribution, and reproduction in any medium, provided the original work is properly cited.

\begin{abstract}
The syntheses of nitrobenzene and p-nitrotoluene directly from benzene, toluene, and $\mathrm{NO}_{2}$ within the pore network of the initially acid-free zeolite NaZSM- 5 are reported for the first time. The active species $\mathrm{NO}_{2}{ }^{\delta+}$, formed by the interaction of $\mathrm{NO}_{2}$ with the $\mathrm{Na}^{+}$ cations present on the internal surface, results in the acid-free electrophilic substitution of the aromatic ring. There are two distinct reservoirs for the reagents: one associated with close proximity to the cation sites and the other associated with the siliceous areas of the pore network. Up to $34 \%$ of the hydrocarbon and $70 \%$ of the available $\mathrm{NO}_{2}$ are reacted at $50^{\circ} \mathrm{C}$. Only the cation associated sites are reactive at low temperature, and there appears to be little mobility between the sites under the reaction conditions. There is no evidence of a second nitration occurring. This represents a novel route to the single nitration of benzene and toluene and for toluene, the generation of the para isomer exclusively. The pore network of the NaZSM-5 restricts the available reaction volume and transition state geometry allowing only the para-substituted product.
\end{abstract}

\section{Introduction}

As part of an investigation into employing heterogeneous catalysis to selectively produce small industrial intermediates, nitrobenzene and para-nitrotoluene were synthesized directly from benzene and toluene and $\mathrm{NO}_{2}$ in the initially acid-free zeolite, NaZSM-5.

Approximately $95 \%$ of the $>1.5 \times 10^{6}$ tonnes of nitrobenzene produced annually is used in the production of aniline [1]. Most of the remainder is used for precursors in rubber, pesticides, dyes, and pharmaceuticals such as Acetaminophen $[1,2]$. Para-nitrotoluene is used in the synthesis of p-toluidine, which in turn is used to manufacture dyes and as accelerators for cyanoacrylate adhesives [3].

ZSM-5 is a medium pore pentasil zeolite $[4,5]$ with two perpendicular channel systems (see Figure 1). The first is a straight channel of elliptical cross section of $0.55 \times$ $0.51 \mathrm{~nm}$, and the second is sinusoidal with dimensions of $0.56 \times 0.53 \mathrm{~nm}$ [6]. Its most valuable industrial process is the isomerization of xylenes to enhance the fraction of para-xylene in the product stream [7-9]. This is thought to result from the aluminosilicate channel wall restricting the available transition state volume and enhancing the diffusion of the para-isomer down the pores [10]. The void space of the channel system easily accommodates para-substituted benzene rings, but is too restricted to allow easy movement of ortho- and meta-substituted species. ZSM- 5 would thus be ideal for the selective formation of para-nitrotoluene.

Economic considerations for industrial intermediates favor selection of the least expensive reagent, hence $\mathrm{NO}_{2}$ for nitration, even at the cost of selectivity. Traditional methods for the nitration of aromatic rings using $\mathrm{NO}_{2}$ involve strong acids to generate $\mathrm{NO}_{2}{ }^{+}$, which is the active entity in an electrophilic substitution of the ring [11, 12]. Use of solidacid catalysts, such as alumina/silica/metal oxides achieves excellent conversions, but with limited ability to enhance the proportion of any isomer $[13,14]$. Acid zeolites have been used successfully as solid-acid catalysts to achieve nitration of aromatics with varying levels of selectivity [1517]. These methods require a high-temperature acid activation step. In contrast, it has been shown that the electrostatic fields of the $\mathrm{Na}^{+}$cations in NaZSM-5 are capable of enhancing the electrophilic character of small molecules adsorbed into the channel system at room temperature [18]. This would allow the use of NaZSM-5 as a heterogeneous nitration catalyst without conversion of the zeolite to an acid form and high-temperature activation of the acid sites. 


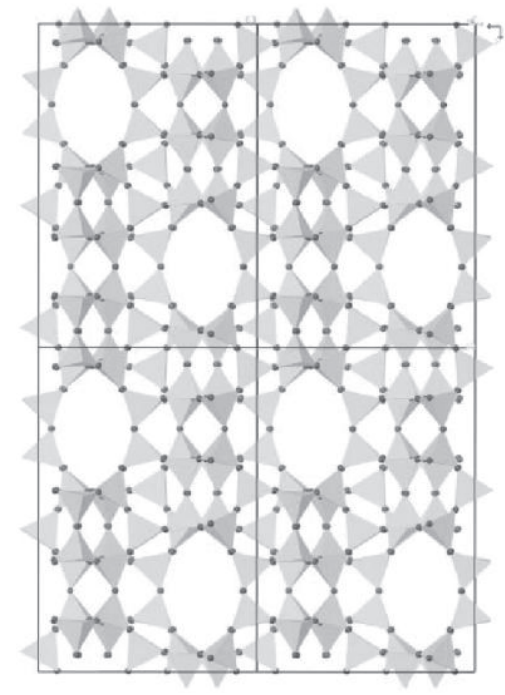

(a)

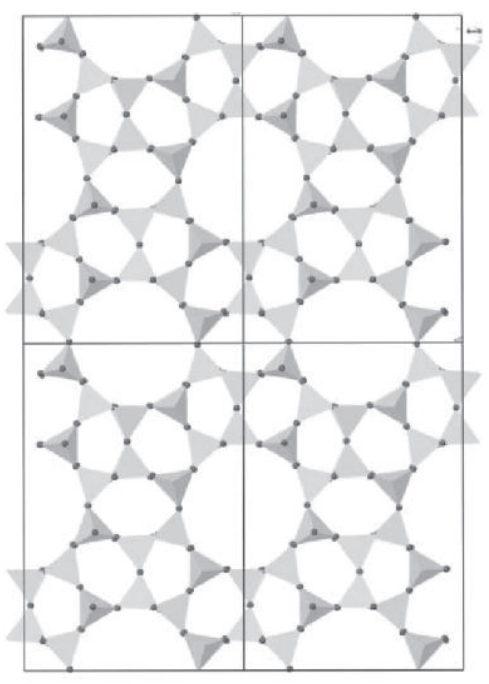

(b)

FIGURE 1: Molecular modeling representation of the two-dimensional pore network for Zeolite ZSM-5.

\section{Experimental}

NaZSM-5 was prepared from commercial $\mathrm{NH}_{4} \mathrm{ZSM}-5$ (Zeolyst, product no. CBV15014, lot no. 15014-1525-63, $\mathrm{SiO}_{2} / \mathrm{Al}_{2} \mathrm{O}_{3}=150$ ) by ion exchanged using sodium acetate. The exchange was repeated until $\mathrm{NH}_{4}{ }^{+}$could not be detected by FT-IR spectroscopy. Thus the $\mathrm{Na} / \mathrm{Al}$ ratio was inferred to be 1. Also, it is important to note that there was no detectable Brønsted acid hydroxyl peak at $3611 \mathrm{~cm}^{-1}$ [19].

The reactions were carried out in 6-9 $\mathrm{mg}(12.5 \mathrm{~mm}$ diameter) self-supporting pellets of neat NaZSM-5 contained in a stainless steel gas cell within a variable temperature vacuum cryostat (Oxford Instruments model DN1714). The wafers were dehydrated overnight at $200^{\circ} \mathrm{C}$ (maximum cryostat temperature, and below the normal $\mathrm{NH}_{4} \mathrm{ZSM}-5$ to HZSM5 conversion temperature of $400-600^{\circ} \mathrm{C}$ ) under vacuum (Varian turbo molecular pump model V-60). The zeolite was exposed to 2.0 torr of either benzene or toluene (Aldrich $99.9 \%$ ) for one half hour at room temperature after which the gas cell was evacuated to below 5 mtorr. The sample was then cooled or heated to the experimental temperature and allowed to stabilize for 1.5 hours. 10.0 torr of room temperature $\mathrm{NO}_{2}$ (Matheson 99.5\%) gas was released into the gas cell, and then after thirty seconds the cell was closed. Time zero for the kinetics corresponds to the initial release of the $\mathrm{NO}_{2}$ into the sample cell.

The gas cell and the cryostat were fitted with $\mathrm{KCl}$ windows to allow the in situ collection of FT-IR spectra. Spectra were collected using an IBM-Bruker IR-44 spectrometer. 100 scans at $1 \mathrm{~cm}^{-1}$ resolution were coadded and ratioed against a background of the empty dehydrated pellet at $25^{\circ} \mathrm{C}$. Time zero for the kinetics was the initial release of $\mathrm{NO}_{2}$ into the cell. 100 scans required approximately $100 \mathrm{~s}$ to collect on the IR44 , and thus each data point in the kinetics plot corresponds to a $100 \mathrm{~s}$ wide time slice.

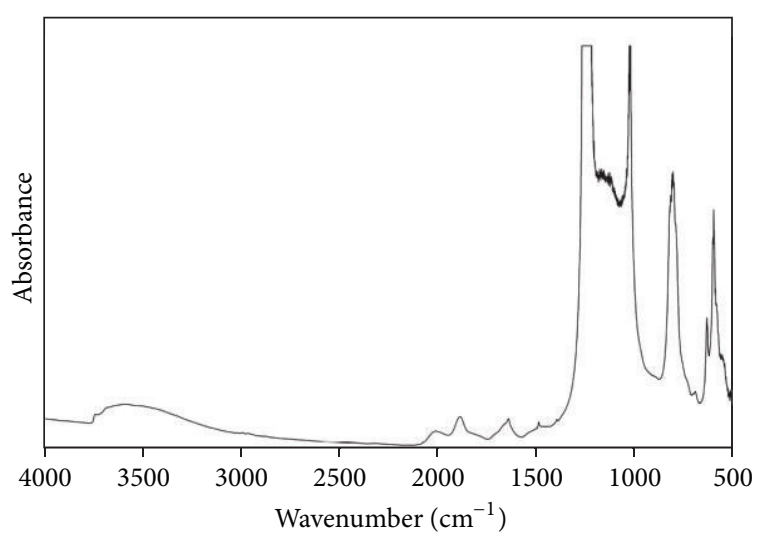

FIGURE 2: FT-IR spectrum of a dehydrated NaZSM-5 pellet. Note: the effective window for monitoring adsorbed species extends from 4000 to approximately $1300 \mathrm{~cm}^{-1}$ because of the intense framework modes below that point.

The identity of the major reaction product was determined by comparison with spectra of authentic samples of nitrobenzene, and ortho-, meta-, and para-isomers of dinitrobenzene and nitrotoluene (all from Aldrich, 99\%) obtained by the vapor-phase loading of a freshly dehydrated clean pellet.

\section{Results and Discussion}

The IR spectrum of the dehydrated NaZSM-5 pellet (see Figure 2) contains several peaks in the $>1300 \mathrm{~cm}^{-1}$ IR window. They are a broad peak at $3588 \mathrm{~cm}^{-1}$ from residual water (OH stretch) in the lattice. This peak has two shoulders at 


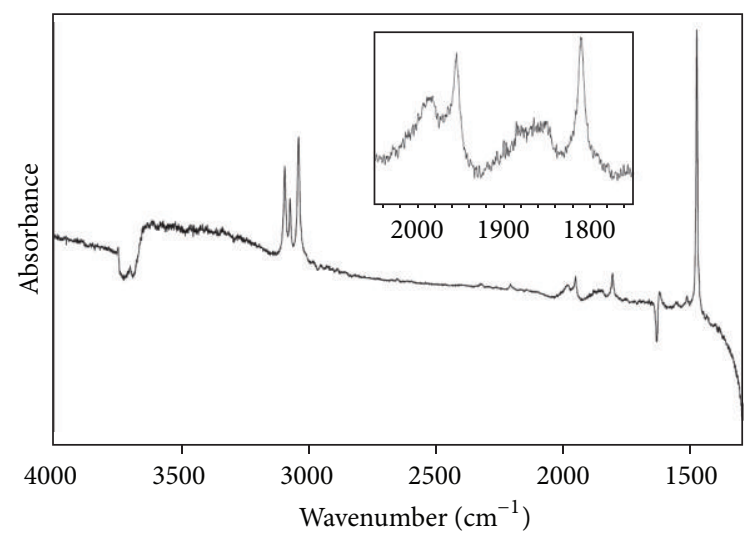

FIGURE 3: FT-IR spectrum ((zeolite + hydrocarbon) - empty zeolite) for benzene adsorbed into the pore network of NaZSM-5 at room temperature.

3739 and $3688 \mathrm{~cm}^{-1}$ corresponding to $\mathrm{SiOH}$ hydroxyls on the surface of the crystallites [19]. Another residual water peak (bend) occurs at $1636 \mathrm{~cm}^{-1}$. A small sharp peak occurs at $1485 \mathrm{~cm}^{-1}$ from trace impurities introduced during ion exchange of the zeolite. The peak at $1392 \mathrm{~cm}^{-1}$ is caused by silicone vacuum grease migrating onto the IR cell windows during the dehydration process.

There are two moderate intensity framework modes at 2006 and $1882 \mathrm{~cm}^{-1}$. Again, there is no IR evidence of Brønsted acid sites at $3611 \mathrm{~cm}^{-1}$ [19]. Adsorption of benzene or toluene into the pellet results in shifts of the framework modes to lower frequency as the lattice distorts to accommodate the hydrocarbon [19]. This may be observed by the slight drop in the baseline of the difference spectrum ((zeolite with hydrocarbon) - empty zeolite) near $1300 \mathrm{~cm}^{-1}$ and the distortion of the baseline near 2006 and $1882 \mathrm{~cm}^{-1}$ (see Figure 3). Similarly the residual water is disturbed leading to a dip in the difference spectrum at $1636 \mathrm{~cm}^{-1}$ and formation of a broad band at $3637 \mathrm{~cm}^{-1}$. The surface $\mathrm{SiOH}$ are also disturbed leading to minima at 3730 and $3688 \mathrm{~cm}^{-1}$.

Adsorption of benzene onto NaZSM- 5 results in new bands at 3094, 3074, 3040, 1985, 1954, 1858, 1809, 1517, 1480, 696 , and $672 \mathrm{~cm}^{-1}$ (see Figure 3). Frequency shifts relative to gas-phase $\mathrm{C}_{6} \mathrm{H}_{6}$ are small [20]. The weak absorption at $1517 \mathrm{~cm}^{-1}$ is assigned to the $v_{7}\left(\mathrm{~b}_{2 \mathrm{~g}}\right)$ ring mode, which is infrared inactive in the gas phase [20]. The appearance of this mode indicates interaction with the zeolite environment that breaks the $\mathrm{D}_{6 \mathrm{~h}}$ symmetry. The two pair of modes at 1985/1858 and 1954/1809 $\mathrm{cm}^{-1}$ (see inset of Figure 3) for $\mathrm{C}_{6} \mathrm{H}_{6}$ indicate two primary adsorption sites. The higher frequency pair is associated with the $\mathrm{Na}^{+}$cation site, while the lower pair corresponds to benzene adsorbed on the "silica" framework. The "silica modes" are much more intense and narrower than for the "cation modes" suggesting that the majority of the benzene is not associated with a cation and that the cation environments are very inhomogeneous.

Infrared spectra obtained upon loading of $\mathrm{C}_{6} \mathrm{D}_{6}$ into NaZSM-5 mirror the effects observed for the parent molecule.

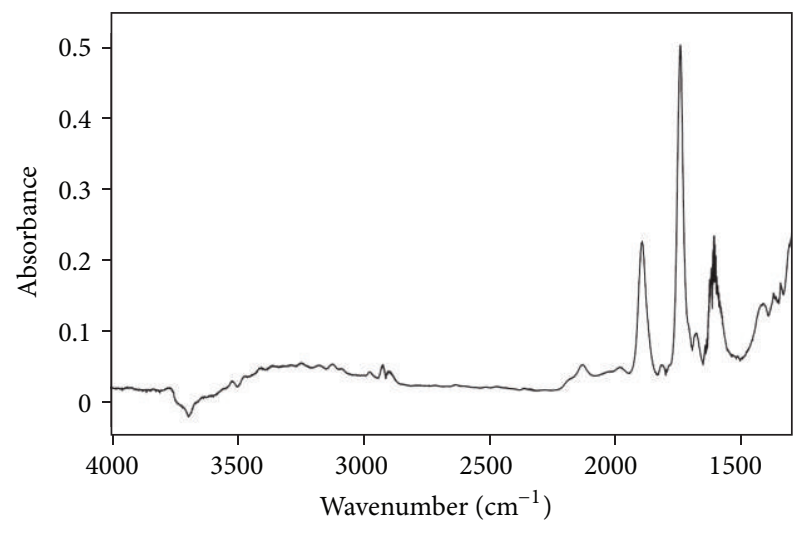

FIGURE 4: FT-IR difference spectrum for $\mathrm{NO}_{2}$ adsorbed into a clean dehydrated pellet of NaZSM-5 at $50^{\circ} \mathrm{C}$.

Bands of the occluded benzene- $\mathrm{d}_{6}$ are at $2389,2285,2270$, 1616,1350 , and $1328 \mathrm{~cm}^{-1}$. The existence of two major types of adsorption sites is supported by the $2285 / 2270 \mathrm{~cm}^{-1}$ splitting of the $v_{12}$ CD stretching mode [19]. Analysis of the spectra suggests that the $2270 \mathrm{~cm}^{-1}$ component is associated with benzene adsorbed on $\mathrm{Na}^{+}$and the $2285 \mathrm{~cm}^{-1}$ peak with adsorption on siliceous parts of the zeolite wall [19]. Infrared bands of toluene adsorbed on the zeolite $(3089,3069,3032$, $2984,2925,2875,1955,1939,1870,1854,1800,1606,1597,1565$, $1523,1496,1452,1379,1340,747,726$, and $694 \mathrm{~cm}^{-1}$ ) are very close to those of the gas-phase molecule. As for benzene, two distinct loading sites are observed. One associated with the $\mathrm{Na}^{+}$cation and one corresponding to adsorption on the silica pore wall.

Adsorption of $\mathrm{NO}_{2}$ into the zeolite favors formation of $\mathrm{N}_{2} \mathrm{O}_{4}$ especially at lower temperature. Three different forms of $\mathrm{N}_{2} \mathrm{O}_{4}$ may be observed in the lattice. Symmetric $\mathrm{O}_{2} \mathrm{NNO}_{2}$ with $\mathrm{D}_{2 \mathrm{~h}}$ symmetry is the predominant specie (intense absorption at $1741 \mathrm{~cm}^{-1}$ ). Since NaZSM-5 is transparent in the region 770 to $630 \mathrm{~cm}^{-1}$, low frequency modes of this species at 742 and $685 \mathrm{~cm}^{-1}$ are observed as well. Asymmetric $\mathrm{O}_{2} \mathrm{NONO}$ with both $\mathrm{D}$ and $\mathrm{D}^{\prime}$ symmetries is also observed at 1807 and $1894 \mathrm{~cm}^{-1}$, respectively [21]. At $25^{\circ} \mathrm{C}$ and $50^{\circ} \mathrm{C}, \mathrm{D}_{2 \mathrm{~h}}$ symmetry $\mathrm{N}_{2} \mathrm{O}_{4}$ is converted to $\mathrm{D}^{\prime} \mathrm{O}_{2} \mathrm{NONO}$ as observed by the loss of intensity of the $\mathrm{D}_{2 \mathrm{~h}}$ form's peaks and the concurrent increase in the peak at $1894 \mathrm{~cm}^{-1}$. This inter conversion is not observed after several hours at $0^{\circ} \mathrm{C}$. D and $\mathrm{D}^{\prime}$ forms differ from each other by the torsion angle about the $\mathrm{O}_{2} \mathrm{~N}-\mathrm{ONO}$ bond [21]. There is no consumption of the $\mathrm{D}$ or $\mathrm{D}^{\prime}$ forms during the reaction with either benzene or toluene.

When the temperature of the zeolite is raised from 0 to $50^{\circ} \mathrm{C}$, the $\mathrm{N}_{2} \mathrm{O}_{4}$ bands diminish. At the same time, there is an intensity increase for absorptions at 2127, 1980 1892, 1677, 1413 , and $1371 \mathrm{~cm}^{-1}$, all of which are assigned to monomeric species formed at the expense of the dimer. Figure 4 shows the spectrum of $\mathrm{NO}_{2}$ loaded NaZSM- 5 at $50^{\circ} \mathrm{C}$ after spectral subtraction of the residual gas-phase $\mathrm{NO}_{2}$. Both nitrogen and oxygen "contact" adsorbed forms of $\mathrm{NO}_{2}$ are observed at 1580 and $1420 \mathrm{~cm}^{-1}$, respectively, which are close to their values on 

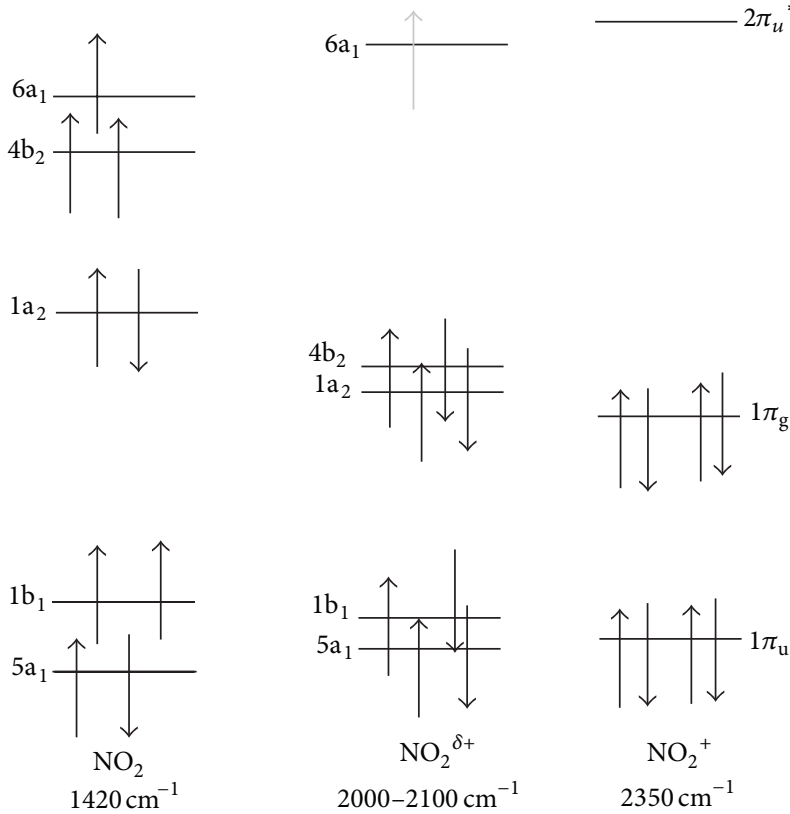

FIGURE 5: Schematic molecular orbital diagram for $\mathrm{NO}_{2}, \mathrm{NO}_{2}{ }^{\delta+}$, and $\mathrm{NO}_{2}{ }^{+}$. The grayed electron represents the diminished electron density in the HOMO because of donation to the zeolite $\mathrm{Na}^{+}$cation. The result is a shift of the vibrational frequency to higher wave number. As $\delta$ increases, so does the frequency. The extent of the donation depends on the local environment of the cation in the zeolite.

silica. The strong band at $1892 \mathrm{~cm}^{-1}$ lies in a region where NO absorbs (gas phase, $1876 \mathrm{~cm}^{-1}$ ) [22]. The species is introduced as an impurity of the reactant gas. There is, however, no evidence of $\mathrm{NO}$ or $\mathrm{N}_{2} \mathrm{O}_{3}$ formation under the experimental conditions.

In addition to rearrangement, charge-transfer products are also found. $\mathrm{NO}_{2}{ }^{+}$has an absorption in the range 2340 to $2380 \mathrm{~cm}^{-1}$ depending in its local environment [23]. No bands were observed in this region. Testova et al. [15] have reported bands at 2345 and $2140 \mathrm{~cm}^{-1}$ in HZSM- 5 while Chao and Lundsford report peaks at 2000 and $2100 \mathrm{~cm}^{-1}$ in $\mathrm{NaY}$ [24]. Comparison with the acetyl radical $[25,26]$ suggests that it may be more appropriate to designate these species as zeolite $\cdots \mathrm{Na}^{(1-\delta)+} \cdots \mathrm{NO}_{2}{ }^{\delta+}$ (abbreviated from here on as $\mathrm{NO}_{2}{ }^{\delta+}$ for brevity) resulting from donation of electron density from the $\mathrm{NO}_{2} \mathrm{HOMO}$ to the $\mathrm{Na}^{+}$when the complex forms. As $\delta$ increases, the peak of the symmetric stretch will shift to a higher frequency (see Figure 5). The broad bands at 2048 and $1983 \mathrm{~cm}^{-1}$ most likely represent these $\mathrm{NO}_{2}{ }^{\delta^{\prime}+}$ and $\mathrm{NO}_{2}{ }^{\delta^{\prime \prime}+}$ species.

Matrix isolated $\mathrm{NO}_{2}{ }^{-}$absorbs at $1244 \mathrm{~cm}^{-1}$ [27] and is thus not directly observable in ZSM-5 zeolite because of obstruction by the framework modes. Partially negative charged $\mathrm{NO}_{2}{ }^{\delta-}$ species most likely give rise to the doublet at 1413 and $1371 \mathrm{~cm}^{-1}$ [28]. The small bands at 1607 and

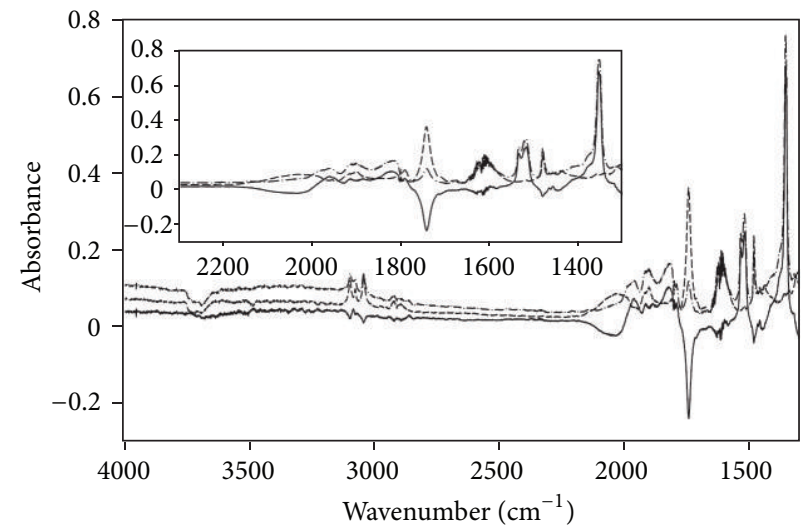

(a)

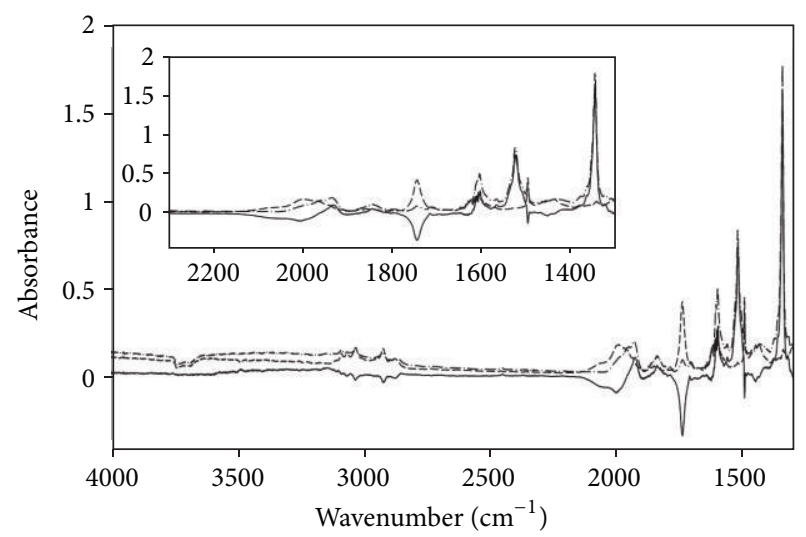

(b)

FIGURE 6: FT-IR spectra for the reaction of (a) benzene and (b) toluene with $\mathrm{NO}_{2}$ at $50^{\circ} \mathrm{C}$. The traces are time $t=0$, the initial exposure of the zeolite plus hydrocarbon to $\mathrm{NO}_{2}$ (dash); after four hours of reaction (dash-dot); difference (solid).

$1677 \mathrm{~cm}^{-1}$ originate from $\mathrm{NO}_{2}$ that interacts only weakly with the zeolite's environment because they are close to the gasphase frequency [29].

In addition to intensity changes in the benzene peaks because of "sweep in" and displacement effects, adsorption of $\mathrm{NO}_{2}$ into benzene-loaded NaZSM- 5 results in the spontaneous loss of reactant peaks and the concurrent growth of new infrared bands at 3083, 2873, 1533, 1520, 1456, 1378, $1352,1319,706,682$, and $682 \mathrm{~cm}^{-1}$ (see Figure 6(a)). These correspond to those for authentic nitrobenzene directly adsorbed into empty NaZSM-5. The reaction of benzene with $\mathrm{NO}_{2}$ is highly temperature dependent. At $0^{\circ} \mathrm{C}$ only 2 3 percent of the initial benzene peak intensity is lost after 240 minutes. This increases to 7 percent at $25^{\circ} \mathrm{C}$ and $34 \%$ at $50^{\circ} \mathrm{C}$ along with a corresponding consumption of approximately $70 \%$ of $\mathrm{N}_{2} \mathrm{O}_{4}$ originally present in the lattice (see Figures 7 and 8). For the $50^{\circ} \mathrm{C}$ experiments, there is also a loss of peak intensity between 2050 and $1980 \mathrm{~cm}^{-1}$ which corresponds to the various positive charge-transfer species of $\mathrm{NO}_{2}$. There is no spectroscopic evidence for a second nitration occurring. Using authentic nitrobenzene adsorbed into the lattice gives no detectable reaction with $\mathrm{NO}_{2}$ at $50^{\circ} \mathrm{C}$ after four hours. 


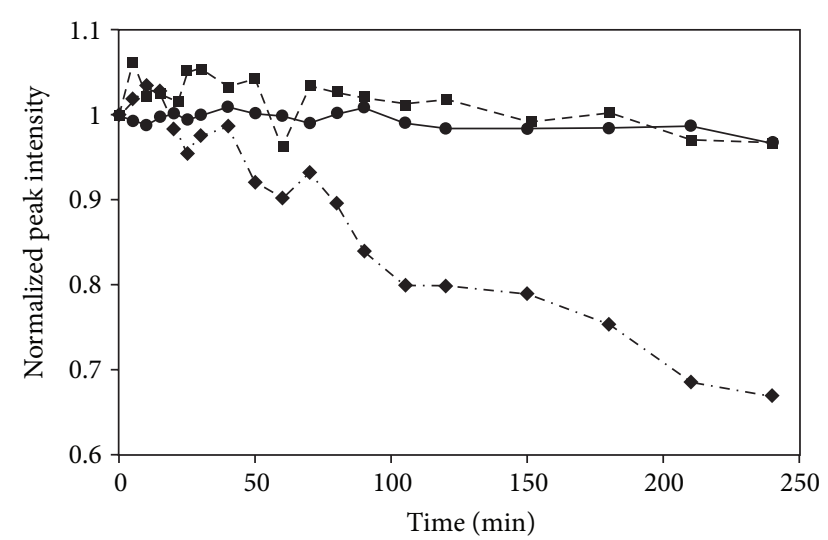

Figure 7: Representative normalized peak intensity versus time plots for the consumption of benzene at $0^{\circ} \mathrm{C}(\bullet), 25^{\circ} \mathrm{C}(\bullet)$, and $50^{\circ} \mathrm{C}$ $(\downarrow)$ for the benzene. Note: the intensity rise above one is the result of "sweep in" effects from the loading of $\mathrm{NO}_{2}$ into the zeolite lattice.

Above $50^{\circ} \mathrm{C}$, the amount of adsorbed $\mathrm{NO}_{2} / \mathrm{N}_{2} \mathrm{O}_{4}$ is reduced, thus limiting the amount of product formed.

Infrared product absorptions followed the expected firstorder growth behavior, except for one of the two components of the intense asymmetric $\mathrm{NO}_{2}$ stretch of nitrobenzene (see Figures 8 and 9). Of the two bands at 1533 and $1520 \mathrm{~cm}^{-1}$, the higher frequency component exhibited a clear induction period. This is attributed to a second site of nitrobenzene inside the zeolite pores since it is also observed when loading an authentic sample of nitrobenzene into NaZSM-5. Experiments with benzene- $d_{6}$ under the same conditions furnished some insight into the origin of this site splitting. The product spectrum of the $\mathrm{C}_{6} \mathrm{D}_{6}+\mathrm{NO}_{2}$ reaction, which agreed well with the infrared spectrum of perdeuteronitrobenzene reported in the literature [30] showed a $v\left(\mathrm{NO}_{2}\right)$ doublet at 1526 and $1511 \mathrm{~cm}^{-1}$. As in the case of the parent isotope, the growth of the higher frequency peak exhibited an induction period. Comparison with the depletion profile of the $v_{12}(\mathrm{CD})$ absorption of $\mathrm{C}_{6} \mathrm{D}_{6}$ at 2285 and $2270 \mathrm{~cm}^{-1}$ suggests a connection between the benzene and nitrobenzene adsorption sites as shown in Figure 9. While the growth of $v_{\text {as }}\left(\mathrm{NO}_{2}\right)$ of $\mathrm{C}_{6} \mathrm{D}_{5} \mathrm{NO}_{2}$ upon $\mathrm{C}_{6} \mathrm{D}_{6}+\mathrm{NO}_{2}$ reaction at $50^{\circ} \mathrm{C}$ shows both a 1526 and a $1511 \mathrm{~cm}^{-1}$ peak, the reaction at $0^{\circ} \mathrm{C}$ results only in growth at $1511 \mathrm{~cm}^{-1}$. The corresponding infrared difference spectrum in the $v_{12}(\mathrm{CD})$ region of $\mathrm{C}_{6} \mathrm{D}_{6}$ reveals that at $0^{\circ} \mathrm{C}$ depletion occurs exclusively at $2270 \mathrm{~cm}^{-1}$. By contrast, at $50^{\circ} \mathrm{C}$, decrease of both the 2285 and $2270 \mathrm{~cm}^{-1}$ peaks is observed (see Figure 9). The $2270 \mathrm{~cm}^{-1}$ site is faster and has a much greater extent of reaction at a given temperature. This suggests that reaction of benzene adsorbed on $\mathrm{Na}^{+}$ cation sites $\left(2270 \mathrm{~cm}^{-1}\right)$ leads to nitrobenzene absorbing at $1526 \mathrm{~cm}^{-1}$, while benzene absorbed on siliceous areas of the zeolite pores is responsible for product growth at $1511 \mathrm{~cm}^{-1}$. This suggests that there are two independent reservoirs of reagents, and under the experimental conditions, there is little interconversion between the two below $50^{\circ} \mathrm{C}$. The reason for this may be that in the "full" zeolite, diffusion slows appreciably. This would also explain that the much-reduced

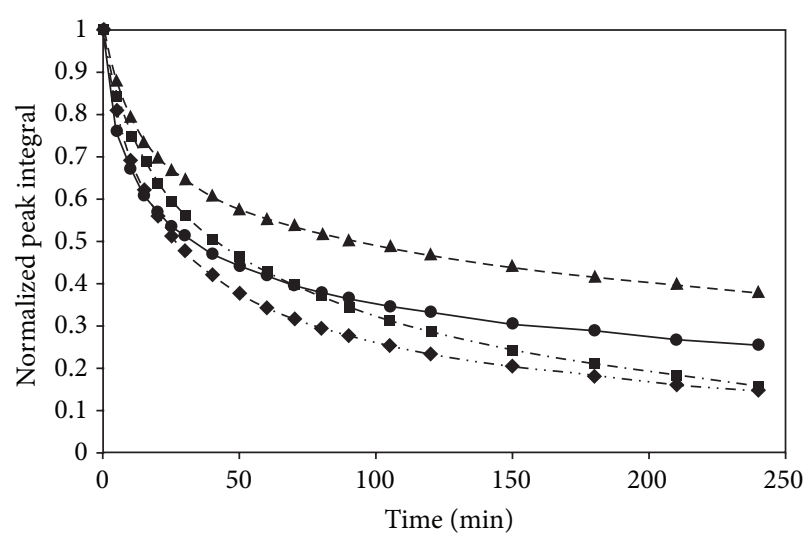

(a)

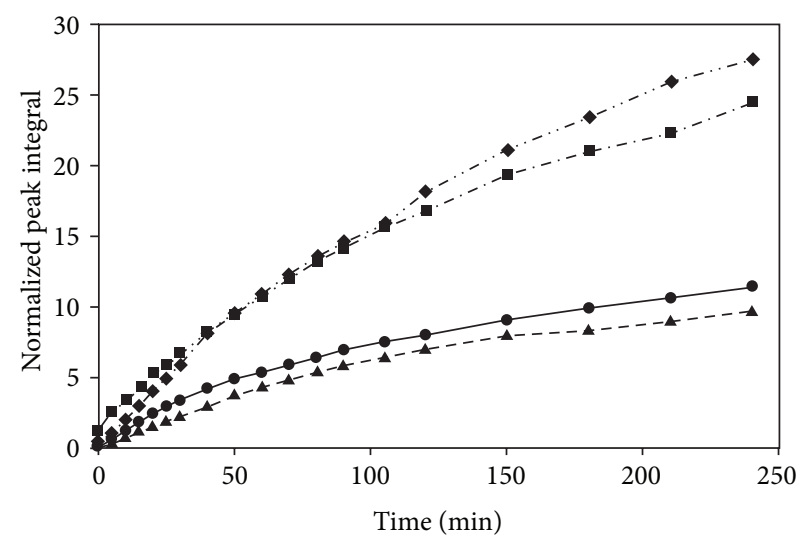

(b)

FIGURE 8: Normalized peak integral versus time plots for (a) the consumption of $\mathrm{N}_{2} \mathrm{O}_{4}\left(1741 \mathrm{~cm}^{-1}\right)$ and (b) the growth of the asymmetric $-\mathrm{NO}_{2}$ stretch for benzene $(\bullet)$, benzene- $\mathrm{d}_{6}(\boldsymbol{\Delta})$, toluene $(\boldsymbol{\square})$, and toluene- $\mathrm{d}_{8}(\diamond)$ at $50^{\circ} \mathrm{C}$.

extent of reaction as only those regents directly adsorbed onto reactive sites are able to react at temperatures below $50^{\circ} \mathrm{C}$.

The induction period may also result from dependence on the side product $\mathrm{H}^{+}$from the more reactive sites. Only when sufficient $\mathrm{H}^{+}$is present in the siliceous areas is the $\mathrm{NO}_{2}{ }^{\delta+}$ sufficiently active for nitration to occur. There is, however, no spectroscopic evidence to for the formation of $\mathrm{HNO}_{2}$ or $\mathrm{NO}_{2}{ }^{+}$during the course of the reaction.

Loading of toluene and $\mathrm{NO}_{2}$ into zeolite NaZSM-5 led to nitration of the arene at about 1.5 times the rate observed for benzene. Studies were again conducted at 0,25 , and $50^{\circ} \mathrm{C}$. Decrease of the toluene bands was accompanied by loss of $\mathrm{NO}_{2}{ }^{\delta+}$ around $2000 \mathrm{~cm}^{-1}$ and symmetric $\mathrm{D}_{2 h} \mathrm{~N}_{2} \mathrm{O}_{4}$ $\left(1741,742,685 \mathrm{~cm}^{-1}\right)$ under concurrent product growth at $1564,1522,1508$ (shoulder), 1345, and $737 \mathrm{~cm}^{-1}$. The spectral changes in the $>1300 \mathrm{~cm}^{-1}$ region are shown in Figure 6(b). Comparison with spectra of authentic samples of o-nitro, $\mathrm{m}$-nitro, and p-nitrotoluene in NaZSM-5 revel that only pnitrotoluene is formed. The pore network of the NaZSM-5 restricts the available reaction volume and transition state geometry allowing only the para-substituted product [18]. As 


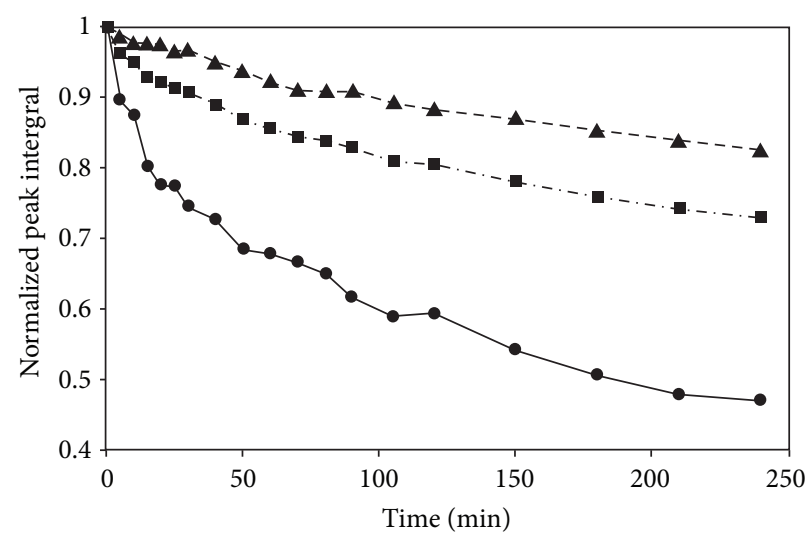

(a)

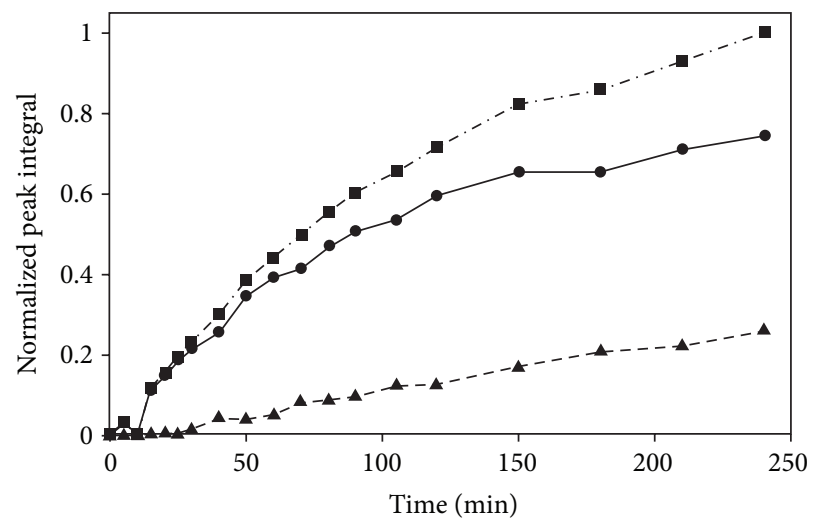

(b)

FIGURE 9: Normalized peak integral versus time plots for (a) the consumption of the two CD modes of benzene- $\mathrm{d}_{6}$ and (b) for the growth of the asymmetric $-\mathrm{NO}_{2}$ stretch separated into $<1520(\bullet)$ and $>1520 \mathrm{~cm}^{-1}(\mathbf{\Lambda})$ components and the sum (ם).

for benzene, there is no evidence for a significant isotope effect.

\section{Conclusions}

Nitrobenzene and p-nitrotoluene were synthesized directly from benzene, toluene and $\mathrm{NO}_{2}$ within the pore network of the initially acid-free zeolite NaZSM-5. The active species is $\mathrm{NO}_{2}{ }^{\delta+}$ formed by the interaction of $\mathrm{NO}_{2}$ with the $\mathrm{Na}^{+}$cations present on the internal surface. There are two distinct reservoirs for the reagents: one associated with close proximity to the cation sites and the other associated with the siliceous areas of the pore network. The extent of reaction is highly temperature dependent with only $2-3 \%$ of the hydrocarbon reacting at $0^{\circ} \mathrm{C}$ and increasing to $34 \%$ ( $>70 \%$ of the available $\mathrm{NO}_{2}$ ) at $50^{\circ} \mathrm{C}$. Only the cation-associated sites are reactive at low temperature, and there appears to be little mobility between the sites under the reaction conditions. There is no evidence of a second nitration occurring. This represents a novel route to the single nitration of benzene and toluene and for toluene, the generation of exclusively the para-isomer.

\section{Acknowledgment}

The author wishes to thank Dr. Heinz Frei, Lawrence Berkeley National Laboratory, for the assistance with the initial effort of this work.

\section{References}

[1] G. Booth, "Nitro compounds, aromatic", in Ullmann's Encyclopedia of Industrial Chemistry, John Wiley \& Sons, New York, NY, USA, 2007.

[2] A. Bhattacharya, V. C. Purohit, V. Suarez, R. Tichkule, G. Parmer, and F. Rinaldi, "One-step reductive amidation of nitro arenes: application in the synthesis of Acetaminophen," Tetrahedron Letters, vol. 47, no. 11, pp. 1861-1864, 2006.

[3] K. Konstantinov, M. Pavlova, M. Glushkov, and L. Dicheva, "Synthesis of methyl 2-cyanoacrylate," Khimiya i Industriya, vol. 5, pp. 218-219, 1982.
[4] R. J. Argauer and G. R. Landolt, U.S. Patent 3702 886, 1972.

[5] F. G. Dwyer and E. E. Jenkins, U.S. Patent 3941 871, 1976.

[6] D. H. Olson, G. T. Kokotallo, S. L. Lawton, and W. M. Meier, "Crystal structure and structure-related properties of ZSM-5," The Journal of Physical Chemistry, vol. 85, no. 15, pp. 2238-2243, 1981.

[7] R. W. Neuzil, U.S. Patent 3558 730, 1973.

[8] R. W. Neuzil, U.S. Patent 3558 732, 1973.

[9] J. J. Ward, "Molecular sieve catalysis," in Applied Industrial Catalysis, B. B. Leach, Ed., vol. 3, p. 271, Academic Press, New York, NY, USA, 1984.

[10] J. Kårger and D. M. Ruthven, Diffusion in Zeolites and Other Microporous Solids, John Wiley \& Sons, New York, NY, USA, 1992.

[11] J. March, Advanced Organic Chemistry, John Wiley \& Sons, New York, NY, USA, 3rd edition, 1985.

[12] S. Takenaka, T. Nishida, and J. Kanemoto, U.S. Patent 4476 335, 1984.

[13] I. Schumaker and K. B. Wang, U.S. Patent 4415 744, 1983.

[14] I. Schumaker, U.S. Patent 4618 733, 1986.

[15] N. V. Testova, L. V. Malysheva, K. G. Ione, E. A. Paukshtis, and N. F. Salakutdinov, "Zeolite catalysis for the solution of environmental problens," in Proceedings of the International Meeting, Yaroslavl, Russia, 1992.

[16] N. F. Salkhutdinov, K. G. Ione, E. A. Kobzar, and L. V. Malysheva, "Gas-phase nitration of aromatic compounds by nitrogen dioxide on zeolites," Zhurnal Organicheskoi Khimii, vol. 29, pp. 546-558, 1993.

[17] L. V. Malysheva, V. Ludmila, E. A. Paukshtis, and K. G. Ione, "Nitration of aromatics by nitrogen oxides on zeolite catalysts: comparison of reaction in the gas phase and solutions," Catalysis Reviews, vol. 37, pp. 179-226, 1995.

[18] S. J. Kirkby and H. Frei, "Highly selective photochemical and thermal chlorination of benzene by $\mathrm{Cl}_{2}$ in NaZSM-5," Journal of Physical Chemistry B, vol. 102, no. 37, pp. 7106-7111, 1998.

[19] H. P. Wang, T. Yu, B. A. Garland, and E. M. Eyring, "Benzene in zeolite ZSM-5 studied by diffuse reflectance infrared spectroscopy," Applied Spectroscopy, vol. 44, no. 6, pp. 1070-1073, 1990.

[20] G. Herzberg, Infrared and Raman Spectra of Polyatomic Molecules, D. Van Nostrand, New York, NY, USA, 1945. 
[21] R. V. St. Louis and B. Crawford Jr., "Infrared spectrum of matrixisolated $\mathrm{NO}_{2}$," Journal of Chemical Physics, vol. 42, no. 3, p. 857, 1965.

[22] G. Herzberg, Spectra of Diatomic Molecules, D. Van Nostrand, New York, NY, USA, 1950.

[23] J. W. Nebgen, A. D. McElroy, and H. F. Klodowski, "Raman and infrared spectra of nitronium perchlorate," Inorganic Chemistry, vol. 4, no. 12, pp. 1796-1799, 1965.

[24] C. C. Chao and J. H. Lundsford, "Infrared studies of the disproportionation reaction of nitric oxide on Y-type zeolites," Journal of the American Chemical Society, vol. 93, no. 1, pp. 7177, 1971.

[25] S. Vasenkov and H. Frei, "Observation of acetyl radical in a zeolite by time. Resolved FT-IR spectroscopy," Journal of the American Chemical Society, vol. 120, no. 16, pp. 4031-4032, 1998.

[26] S. Vasenkov and H. Frei, "Time-resolved study of acetyl radical in zeolite NaY by step-scan FT-IR spectroscopy," The Journal of Physical Chemistry A, vol. 104, no. 18, pp. 4327-4332, 2000.

[27] D. E. Milligan and M. E. Jacox, "Matrix-isolation study of the interaction of electrons and alkali metal atoms with various nitrogen oxides. Infrared spectra of the species $\mathrm{NO}^{-}, \mathrm{NO}_{2}^{-}$, and $\mathrm{N}_{2} \mathrm{O}_{2}^{-}$, The Journal of Chemical Physics, vol. 55, no. 7, p. 3404 , 1971.

[28] P. H. Kasai and R. Bishop Jr., "Electron spin resonance study of nitric oxide adsorption on Linde type Y zeolites," Journal of the American Chemical Society, vol. 94, no. 16, pp. 5560-5566, 1972.

[29] G. Herzberg, Infrared and Raman Spectra of Polyatomic Molecules, D. Van Nostrand, New York, NY, USA, 1945.

[30] J. D. Laposa, "Vibrational spectra of nitrobenzene- $d_{5}$ " Spectrochimica Acta A, vol. 35, no. 1, pp. 65-71, 1979. 

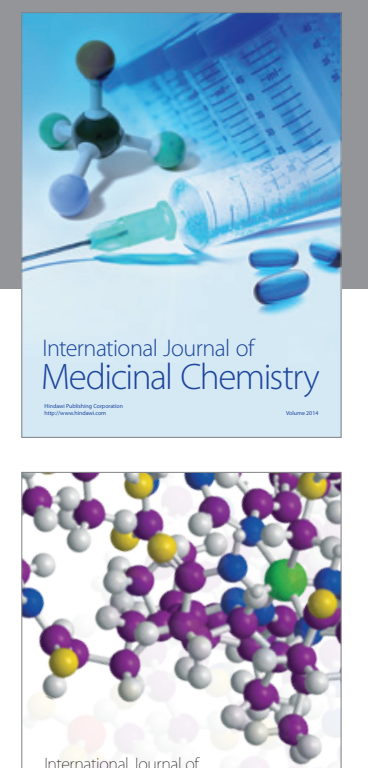

\section{Carbohydrate} Chemistry

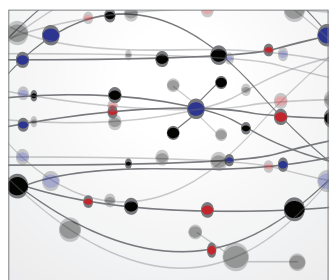

The Scientific World Journal
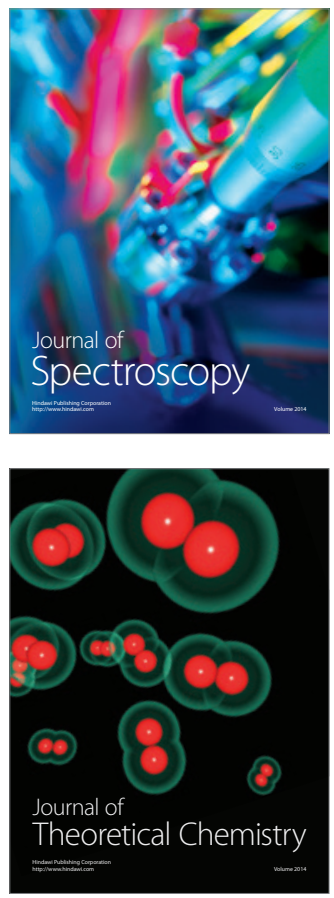
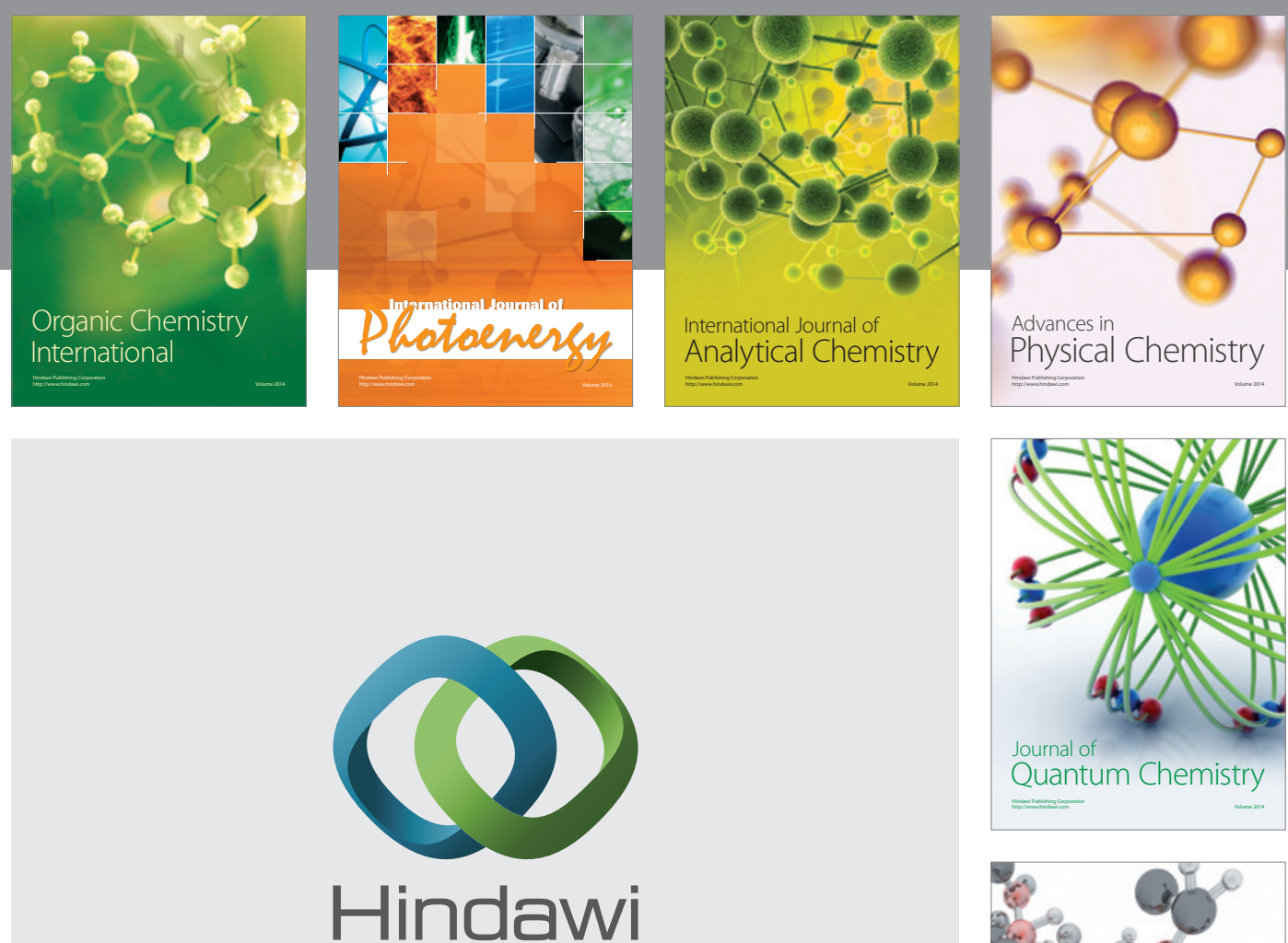

Submit your manuscripts at

http://www.hindawi.com

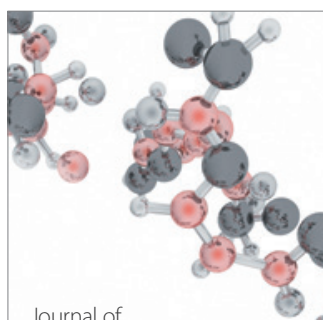

Analytical Methods

in Chemistry

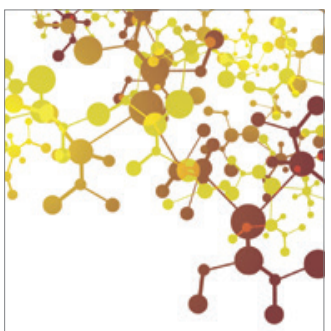

Journal of

Applied Chemistry

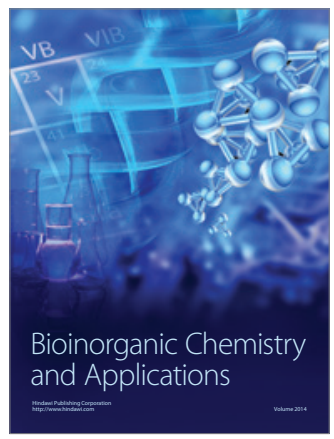

Inorganic Chemistry
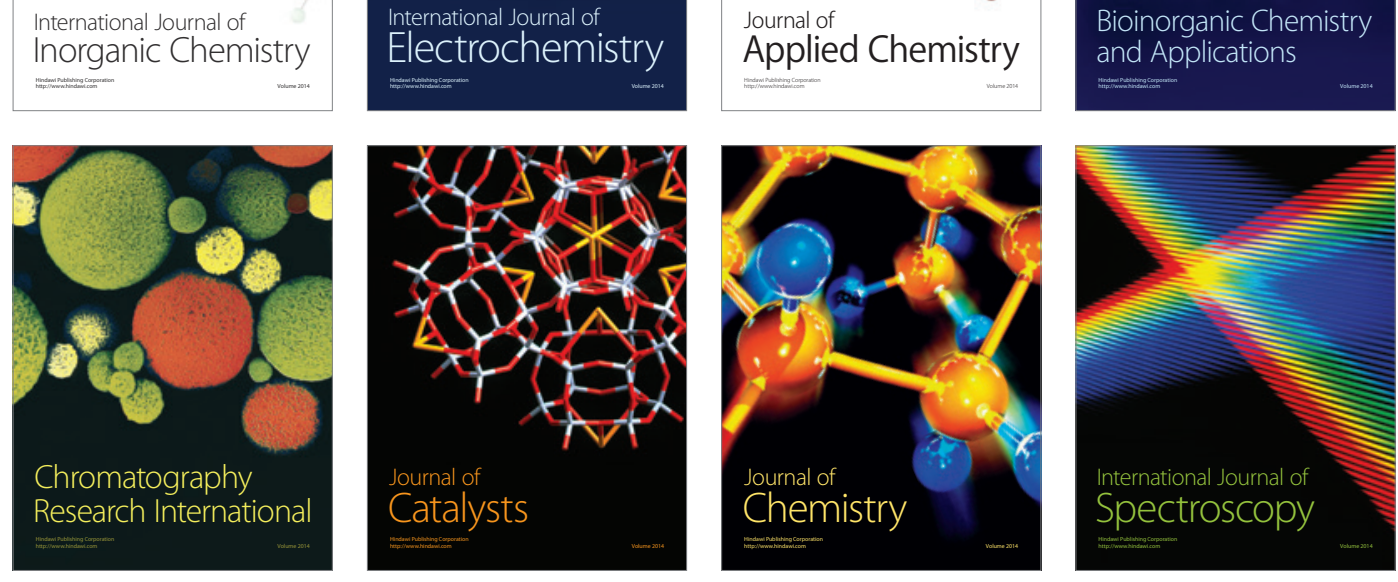